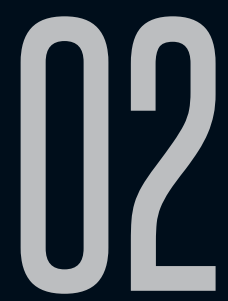

\title{
ONZE HISTÓRIAS E UM SEGREDO: DESVENDANDO AS LENDAS AMAZÔNICAS. TAÍSA APARECIDA CARVALHO SALES. 2016
}

Jamille da Silva Santos (UFU)

Recebido em 02 mai 2019. Jamille da Silva Santos é Doutoranda em Estudos Aprovado em 08 mai 2019. Literários da Universidade Federal de Uberlândia UFU. Mestre em Linguística pelo programa de Pós graduação em Lingüística - PPGlin da Universidade Estadual do Sudoeste da Bahia (2014). Possui Especialização em Lingua Brasileira de Sinais (LIBRAS) pelo Claretiano Sistema de Ensino (2018). Possui graduação em Letras Vernáculas pela Universidade Estadual do Sudoeste da Bahia (2012), Campus de Vitória da Conquista - Bahia. É membro dos Grupos de Pesquisa: Estudos sobre o Discurso e o Corpo grudcorpo/CNPq e do Grupo de Pesquisa em Espacialidades Artísticas GPEA / CNPq. Membro do LABEDISCO - Laboratório de Estudos do Discurso e do Corpo. 
O livro Onze histórias e um segredo: desvendando as lendas amazônicas, publicado no ano de 2016, foi organizado pela Professora Ms.a Taisa Aparecida Carvalho Sales - professora, em exercício provisório, de Libras e Tradução no curso de Letras da Universidade Federal de Goiás (UFG) e efetiva da Universidade Federal do Amazonas (UFAM) - em conjunto com os alunos do 40 período

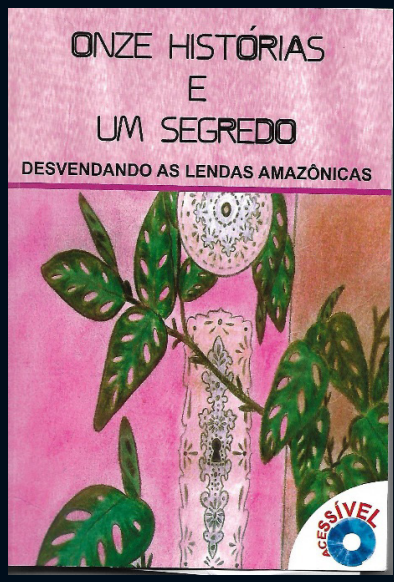
de Letras/Libras da UFAM. Essa coletânea foi escrita pelos alunos como uma proposta apresentada na disciplina "Literatura em Libras", ministrada no ano de 2015.

Como resultado de tamanha dedicação, somos apresentados a um conjunto de onze lendas vinculadas à cultura da Amazônia, que são reescritas levando em consideração a cultura indígena e a cultura surda. As lendas trabalhadas na obra foram: "A cobra grande"; "Mapinguari"; "Lenda do Uirapuru"; "O boto cor-de-rosa surdo"; "Lenda da Vitória-Régia"; "A lenda da Mandioca"; "A lenda do Guaraná"; "A lenda do Pirarucu"; "A lenda da lara"; "Kauane uma guerreira surda" e "O amor faz nascer um povo: a lenda da Família Baré Surda". E, ao final do livro, ganhamos o segredo, que se trata de um glossário da língua de sinais escrita - SignWriting - contendo os principais vocabulários utilizados dentro da obra.

As lendas que foram apresentadas no livro supracitado são reescritas pelos autores levando em consideração as questões que envolvem a comunidade surda. Assim, somos apresentados a temáticas como a falta de aceitação do próprio surdo e de sua 
comunidade - família, tribo, sociedade na qual está inserido -, o lugar do surdo como um ser diferente que possui algum defeito e a dificuldade do surdo em se comunicar em sociedade. As lendas sempre trazem uma solução para tais dilemas, que, em sua maior parte, são resolvidos quando a comunidade indígena decide aprender a língua de sinais e inserir o surdo em seu ambiente. Recorrentes dentro da comunidade surda na sociedade, as dificuldades de se comunicar, de se fazer entendido e entender o outro têm sido uma luta constante, juntamente com a aceitação da língua de sinais como primeira língua e o português como segunda língua escrita para o surdo.

A cada passagem de página, vemos o cuidado na realização e adaptação da obra para que essa não apenas apresentasse a cultura surda, como também fosse acessível para a comunidade surda. A obra é apresentada em quatro formas distintas, o Português que é colocado primeiramente, sendo esse diagramado em uma fonte maior do que costumamos encontrar em obras literárias, o que possibilita para o portador de baixa visão uma boa leitura; a segunda forma é a LIBRAS escrita - SignWriting -, que, apesar de ser uma forma de comunicação ainda pouco usada dentro da comunidade surda, a autora traz como possibilidade de leitura, apresentando o texto que se encontra em Português na LIBRAS escrita; a terceira versão se encontra em forma de vídeo, colocado dentro do livro por meio de um $\mathrm{CD}$, trazendo uma singularidade própria, pois exibe as quatro formas de comunicação em sua apresentação; as duas já mencionadas e a terceira propriamente dita, que é a narrativa oral feita por um locutor que relata o que aparece na tela em escrito; e, finalmente, a quarta, que diz respeito aos intérpretes sinalizando 
a narrativa na língua de sinais. Desse modo, na medida em que o texto aparece na tela em português e em SignWriting, juntamente com a imagem e com um intérprete sinalizando o que está sendo apresentado, a obra torna-se acessível para os surdos, cegos e surdos-cegos simultaneamente.

Outro fator de importante relevância dentro da obra são as ilustrações feitas por Edilson Morais e Silva, que complementam o texto escrito, o que é muito significativo para o surdo, pois, como sabemos, ele é extremamente visual e, por isso, todas as contribuições, como a sinalização e as ilustrações, são importantes para a compreensão textual, já que, em sua maioria, eles não possuem uma total fluência no Português, que deve ser sua segunda língua.

A primeira adaptação a que somos apresentados é da lenda "A Cobra Grande", realizada por Arlice Lopes Monteiro, que narra a história de Taiguara e Ubiraci, irmãos que eram amaldiçoados por serem gêmeos. De acordo com a lenda, as tribos indígenas acreditavam que gêmeos traziam azar para toda a tribo e, sendo assim, todas as vezes que nasciam gêmeos eles deveriam ser mortos para afastar qualquer maldição para aquela comunidade indígena. Dessa maneira, os gêmeos são jogados no rio para morrer, mas são salvos pela correnteza que os leva para a margem, onde crescem. Apesar de sobreviventes, os irmãos carregam marcas pelo fato de terem nascido ao mesmo tempo: Taiguara se transforma em cobra grande nas noites de lua cheia e sai devorando pessoas e virando embarcações; sua irmã Ubiraci nascera surda e, como não conseguia se comunicar com as pessoas a sua volta, vivia sempre afastada e revoltada com todos ao seu redor. No entanto, 
a maldição de Taiguara pode ser rompida desde que ele realize um ato de bondade com algum familiar, o que ocorre quando ele descobre uma comunidade indígena surda, aprende a língua de sinais e a ensina para sua irmã, que consegue se comunicar com seus semelhantes e passa a se sentir aceita e inserida socialmente.

A segunda lenda é a do "Mapiguari", reescrita por Rubens Mesquita da Silva Junior, que relata a vida de Teça, um indiozinho que nascera surdo e, por esse motivo, não consegue se comunicar com sua tribo, mesmo sendo aceito por ela, pois o Cacique acredita que Tupã, em sua sabedoria, fez todos diferentes e que as diferenças trazem qualidades que devem ser respeitadas. Entretanto, o Cacique não consegue fazer com que Teça se sinta inserido dentro da comunidade e, com o passar do tempo, o indiozinho fica mais solitário e revoltado por não conseguir ouvir e falar com sua tribo. Em uma tentativa de vocalizar, Teça começa a emitir sons altos e agudos que incomodam a todos e, conforme o índio cresce, esses sons se tornam mais altos e constantes, ficando insuportável para toda a tribo, que pede auxílio a Tupã para resolver o problema. Desse modo, o deus aparece em sonho para Teça e explica que ele é surdo e que possui uma linguagem própria. Deus começa a ensinálo, porém o índio se recusa e fica cada dia mais revoltado, levando a sua tribo ao desespero, de tal forma que Tupã resolve castigar Teça e o transforma em um monstro com um único olho e uma só boca que grita pela floresta, sendo chamado de Mapinguari. Porém, mesmo transformado em mostro, o índio não se conforma com sua situação, o que faz com que Tupã envie uma índia para enfeitiçá-lo e ensiná-lo a língua de sinais. Assim, Mapinguari se acalma e passa a ser o guardião da floresta guardando seu grito. 
A próxima narrativa é a "Lenda do Uirapuru", que tem sua adaptação feita por Sara Vitor Magalhães, e apresenta a história de Kaolin, filha do cacique da tribo que nascera surda. Um certo dia, a tribo de seu pai recebe a visita de um valente guerreiro, Teçá, que vem de uma tribo distante, onde os habitantes são surdos, e, ao serem apresentados, Teçá e Kaolin se apaixonam imediatamente, porém a índia já se encontrava prometida a outro guerreiro de sua tribo. No entanto, o amor dos dois era tão forte que eles desobedecem às ordens do Cacique e se encontram às escondidas, até o momento em que são descobertos e o cacique decide acelerar o casamento de sua filha com o guerreiro de sua tribo, expulsando Teçá. Porém, Tupã já aprovara a união de Teçá com Kaolin e decide transformar o seu pai em um passarinho para que possa deixar o casal ser feliz. Assim, Teçá e Kaolin se casam e se mudam para a tribo de Teçá, onde vive uma comunidade de índios surdos, e são felizes. $\mathrm{O}$ pai de Kaolin se metamorfoseia em Uirapuru e acompanha o casal para todos os lados cantando em forma de pedido de perdão.

"O Boto cor-de-rosa surdo" expõe uma adaptação realizada por Suelem Maquiné Rodrigues, que narra a vida de Inaiê, uma índia muito observadora que adorava passar os dias observando a paisagem a sua volta. Porém, Inaiê vivia sempre triste porque ela não conseguia se comunicar com as pessoas de sua tribo e não entendia como sua comunidade se entendia; ela percebia que gesticulavam a boca, porém não entendia nada, e a única pessoa com quem ela conseguia ter uma relação de entendimento era com sua mãe, pois as duas se utilizavam de gestos combinados entre elas para estabelecer uma forma de comunicação, mas a indiazinha vivia triste por não ser entendida e todos os dias se dirigia à beira do 
rio para chorar. Todavia, em certo dia, saiu do rio um moço muito bonito e encantador que deslumbrou Inaiê imediatamente, e esse moço se comunicava com as mãos, com o rosto, utilizando-se de todo seu corpo para se fazer entender. O tempo foi passando e os dois se encontravam todas as noites de lua cheia à beira do rio, e o moço ensinou à Inaiê a sua língua. No entanto, certo dia, o moço não apareceu mais, deixando a índia muito triste e solitária, até que se passaram as luas e ela descobriu que estava grávida. Um tempo depois nasceu um curumim surdo, um Apoema, o filho do boto, e para que seu filho não ficasse triste, Inaiê ensinou a língua de sinais para toda a tribo.

A quinta história apresentada é "Lenda da Vitória-régia", narrativa adaptada por Suelem Maquiné Rodrigues, que apresenta a vida de Naara, uma índia que nasceu surda. Por medo de ser amaldiçoada, sua mãe a entrega para o Pajé da tribo, que a cria como filha. Assim, Naara só consegue se comunicar com o Pajé e por meio de gestos combinados. Com medo de sofrer agressões da tribo por ser surda, Naara só sai para passear à noite, sendo as noites de lua cheia suas favoritas. No entanto, o Pajé começa temer o encanto que a índia tem pela lua e uma noite ele conta para ela a verdadeira história da lua, dizendo que na verdade se trata de um valente guerreiro, Jaci, e que as estrelas são suas namoradas. Ele conta que, como Jaci é muito vaidoso, ele costuma conquistar as moças mais bonitas e levá-las para viver com ele em forma de estrelas. Todavia, Naara já estava apaixonada pela lua e, em certa noite, Tupã permite um encontro entre os dois enamorados, o que faz com que ela se apaixone ainda mais e, a partir desse momento, a índia passa todas as noites em busca da lua, pedindo que ela a leve. 
Em uma noite de lua cheia, Naara se depara com o reflexo da lua no meio do rio e se joga atrás do seu amor e, desse momento em diante, nunca mais foi encontrada. No local em que o fato ocorreu, nasceu uma linda planta que foi nomeada de Vitória-régia.

A sexta narrativa apresentada é "A lenda da mandioca", escrita por Tereza de Jesus Albuquerque Moreira, por meio da qual somos apresentados à história de Mani, filha de índia com o deus Tupã. Em um certo dia, a filha do cacique aparece grávida sem saber de quem. A menina era prometida ao deus Tupã, o que deixa seu pai furioso, sendo aplacada sua fúria só com a aparição do deus em sonho falando que a criança era especial e um presente dele para tempos difíceis. Porém a menina nascera surda e, para algumas tradições indígenas, qualquer deficiência é sinal de fraqueza, sendo necessário o sacrifício da criança. O Pajé, então, reúne a tribo, conta sobre seu sonho e decreta que Mani, a menina que nascera branca e surda, era protegida. Mas em uma certa manhã sua mãe a encontra morta em sua rede, o que deixa toda a tribo muito triste. Eles enterram a menina no meio da tribo em uma oca, e, com o passar do tempo, no local em que Mani foi enterrada nasce uma planta nunca vista, que possuía uma raiz branca e saborosa, nomeada de Mani oca, que significa transformação de Mani. No futuro, tornou-se a mandioca, um alimento típico das tribos em todo o país.

A próxima narrativa adaptada é "A lenda do guaraná", feita por Eduardo de Souza Melo. O autor apresenta uma narrativa que se passa dentro da tribo Maués, onde um casal deseja muito ter um filho e não consegue. Após várias tentativas, eles pedem a Tupã que Ihes conceda a graça. Pouco tempo depois, eles recebem a 
dádiva de ter um lindo menino, Cauê - aquele que é bom e age com inteligência -, que fora agraciado por Tupã com o dom de conversar com animais e plantas e ajudar a todos eles, tornando-se muito querido. Assim, por ser muito amado, Cauê desperta a inveja de Jurupari, deus da escuridão, que resolve tomar o dom dado por Tupã. Então, em um susto, ele deixa o menino sem ouvir e sem falar, de modo que Cauê não consegue mais se comunicar com a floresta nem com sua tribo, o que o deixa, assim como todos ao seu redor, muito triste. Não aguentando ver a tristeza que tomara conta da floresta, Tupã resolve agraciar Cauê com o dom das línguas de sinais para que ele pudesse, novamente, comunicar-se com todos a sua volta. Desse modo, sua tribo aprende a língua de sinais, e a paz volta para a tribo. Com o passar do tempo, Cauê morre, e Tupã resolve homenageá-lo, fazendo brotar uma árvore nunca vista na região, com frutos vermelhos e olhos bem pretos iguais ao índio: a árvore do guaraná.

A lenda a seguir foi reescrita por Francisco Pereira de Amorim com base na história do Pirarucu. O Pirarucu era um grande guerreiro indígena conhecido por sua valentia, mas também por sua vaidade e arrogância, principalmente com os que eram diferentes. Em sua tribo, existia um índio surdo, o lberê, e Pirarucu acreditava que ele não merecia o dom da vida por ser diferente de todos ali. No entanto, Iberê possuía o dom de se comunicar com os deuses e, utilizando-se desse dom, ele pede a Tupã que resolva a situação com Pirarucu, uma vez que ele não aguentava mais ser desrespeitado e agredido. Após algumas tentativas de conversa sem resultado, Tupã resolve castigar o Pirarucu e lança sobre a terra uma terrível tempestade que arrasta o índio para o rio, 
local em que o deus o transforma em um peixe grande, escuro, de cabeça chata e calda vermelha e que serviria de alimento para os outros. Em seguida, como forma de proteger lberê, Tupã o guia para uma tribo que possuía pessoas surdas e que aceitavam e se comunicavam por meio da língua de sinais.

A nona lenda apresentada narra a história da lara, e a adaptação é realizada por Jéssica Amaral Morais, que relata o nascimento de uma linda indiazinha, filha do Cacique e uma guerreira; a menina assim que cresce começa a chamar a atenção para os seus dons de caça. Como ela era surda, isso a tornava extremamente silenciosa e hábil com as mãos e olhos, de modo que ela conseguia as melhores caças, o que despertou a inveja em seus três irmãos que, consumidos por esse sentimento, resolveram dar sumiço com a índia. lara, tomada de raiva dos irmãos, vai até a árvore grande e gesticula, pedindo que ela resolva a situação com eles. Ela arranca um galho e com ele faz um chá e oferece para seus irmãos. No outro dia, eles somem, e em seus lugares crescem três árvores. lara, sentida pelo o ocorrido, corre até árvore, gesticulando para que ela traga de volta seus irmãos e que ela seja punida, não eles. Logo em seguida, os irmãos voltam à forma normal, e lara se transforma em uma linda sereia que habita o Rio Amazonas.

A próxima releitura é "Kauane, uma guerreira surda", feita por Lilian Araújo Cerqueira, que conta a história de uma tribo guerreira constituída somente por mulheres. Dentro dessa tribo, não era permitida a presença masculina, e lá vivia Kauane, uma linda indiazinha surda que sonhava em ser guerreira, porém, por causa da surdez, ela não conseguia se comunicar com as outras guerreiras, que não a aceitavam nos treinamentos. Mas Kauane 
insistia e treinava sozinha, até que, certo dia, enquanto treinava, foi vista por Acauã, um guerreiro surdo que a observava, mas não sabia como ajudar. Ele vinha de uma tribo onde vários índios eram surdos e a língua de sinais era respeitada, porém, como ele não podia se aproximar de Kauane, não tinha ideia de como ensinar a ela a língua. Certo dia, pediu auxílio a Tupã, que mostrou a imagem do índio em sonho para Kauane, fazendo com que ela não o expulsasse quando o visse, e foi o que aconteceu. Assim, os dois ficaram amigos e ele ensinou a língua de sinais para ela, que repassou para todas as índias e fez com que elas a respeitassem como guerreira. No entanto, como sua tribo não aceitava a presença masculina, Kauane resolveu ir embora com Acauã para a tribo dele, onde foram felizes.

A última lenda adaptada é "O amor faz nascer um povo: a lenda da família Baré surda", reescrita por Nara Neiva Araújo Costa. A narrativa conta a história de um europeu escrivão da Companhia Francesa que, em passagem pelo Brasil, encanta-se com as belezas das índias e foge de sua embarcação, porém vai parar em uma tribo unicamente feminina que resolve se beneficiar de sua presença para procriação e, assim, o europeu, batizado pelas índias de Mir-bóia, se deita com todas as índias da tribo, até a última, Tipa. Eles começam uma relação, e logo Mira-bóia descobre que Tipa é surda. Como conhecedor das línguas de sinais francesas, ele resolve ensinar para ela e, com a convivência, os dois se apaixonam e resolvem fugir juntos para a nascente do Rio Negro, e lá se estabelecem e geram um filho, Baré, sendo os descendentes de Baré os fundadores da cidade de Manaus.

Por último, somos presenteados com uma surpresa que, como já adiantamos, trata-se de um glossário do português para 
- SignWriting, contendo algumas palavras utilizadas dentro das narrativas, possibilitando uma melhor leitura além de conhecimento da língua escrita de sinais.

A obra é classificada como acessivel e desenvolve muito bem essa função quando busca trazer de várias formas as adaptações das lendas amazônicas para a comunidade surda, mostrando, dentro das narrativas, questões caras para a comunidade, como a comunicação, ou a falta de comunicação, o preconceito por parte dos ouvintes, o pensamento de inutilidade em relação ao surdo, a aceitação da língua de sinais como primeira língua do surdo e, só depois e por meio dela, o aprendizado do português escrito. A obra busca mostrar, por meio das releituras, a dura realidade da comunidade surda e algumas formas de resolução desse impasse. Em todas as narrativas existe um final feliz, e esse é o final feliz tão desejado pela comunidade, um final em que existam mais narrativas dessa forma e uma aceitação do surdo. 